\title{
Preparation of Calcium Carbonate Nanoparticles: Adsorption and Desorption Behavior of Organic Matter $^{+}$
}

\author{
Payam Zolfagharian, Gülay Arslan, Selda Yiğit-Hunce and Elif Soyer * \\ Environmental Engineering Department, Marmara University, Istanbul 34722, Turkey; \\ payam.zolf@gmail.com (P.Z.); gulay.arslan@marmara.edu.tr (G.A.); y_seldayigit@yahoo.com (S.Y.-H.) \\ * Correspondence: elif.soyer@marmara.edu.tr; Tel.: +90-216-348-0292 \\ + Presented at the 3rd EWaS International Conference on "Insights on the Water-Energy-Food Nexus", \\ Lefkada Island, Greece, 27-30 June 2018.
}

Published: 30 July 2018

\begin{abstract}
In this research the adsorption of organic matter onto calcium carbonate $\left(\mathrm{CaCO}_{3}\right)$ nanoparticles was studied. $\mathrm{CaCO}_{3}$ nanoparticles were prepared by purging $\mathrm{CO}_{2}$ gas into lime slurry. Progress of the reaction was monitored by online measurement of $\mathrm{pH}$ and conductivity. Prepared particles were contacted with organic matter synthetic solutions. Organic matter removal rates during adsorption were higher in samples with a high initial organic matter concentration. This result would be a promising solution strategy for the problem of management of flows collected in the treatment concentrates of membrane filtration plants.
\end{abstract}

Keywords: calcium carbonate particles; humic acid; organic material; adsorption

\section{Introduction}

Decomposition of organic substances results in the formation of high molecular weight humic substances that are known as natural organic matter (NOM). One of the major concerns that treatment plant operators have today is NOM. It is a major precursor to the formation of disinfection by products (DBPs), it facilitates the transport of organic and inorganic pollutants, and enhances biological growth in distribution systems [1,2]. Researchers have found that the formation of DBPs is directly proportional to the concentration of organic carbon in water. Removal of organics from water during treatment processes and before chlorination usually requires the addition of high amounts of chemicals. This process is known as enhanced coagulation. The other removal methods are adsorption and membrane filtration. High cost of chemicals used in enhanced coagulation and the formation of sludge, problems arising the use of powdered activated carbon during adsorption such as clogging in granular filters and performance loss encountered in membrane filtration because of organic fouling are among the concerns in selecting the appropriate technique for the removal of organic matter. Calcium-containing composite materials [3] and surface charge modified calcium carbonate particles [4] have been used in previous researches for the removal of organic matter from solutions. $\mathrm{CaCO}_{3}$ particles were integrated in coagulation-flocculation process as a neutralizer and coagulant aid [5].

This research aims to investigate the use of calcium particles in adsorption of organic matter from waters. Effectiveness of the methods employed in preparation of particles and the repeated use of particles in removal of organic matter were also studied. 